\title{
TRANSMISSIBLE GASTROENTERITIS VIRUS AND PORCINE RESPIRATORY CORONAVIRUS: MOLECULAR CHARACTERIZATION OF THE S GENE USING cDNA PROBES AND NUCLEOTIDE SEQUENCE ANALYSIS
}

\author{
Daral J. Jackwood, Insoo Bae, Renee J. Jackwood, and Linda J. Saif \\ Food Animal Health Research Program \\ The Ohio State University \\ Ohio Agricultural Research and Development Center \\ Wooster, Ohio 44691
}

\begin{abstract}
Two transmissible gastroenteritis virus (TGEV, Miller strain) cDNA clones were identified and their nucleotide sequences determined. The clones were non-overlapping and were located in the $5^{\prime}$ region of the $\mathrm{S}$ glycoprotein gene. The TGEV clone $\mathrm{pE} 21$ contained $381 \mathrm{bp}$ of the $\mathrm{S}$ glycoprotein gene and had $>98 \%$ nucleotide and amino acid sequence homology with the Purdue (P115) strain of TGEV and over $87 \%$ sequence homology with feline infectious peritonitis virus (FIPV). The TGEV clone, pD24, contained 267 bp of the S glycoprotein gene. It had $>98 \%$ nucleotide and amino acid sequence homology with P115 but only a $49 \%$ nucleotide sequence homology and a $24 \%$ amino acid sequence homology with FIPV. Using dot blot hybridization, a probe prepared from pD24 could differentiate TGEV from the antigenically related coronaviruses, FIPV, feline enteric coronavirus and canine coronavirus. This probe could also differentiate TGEV from porcine respiratory coronavirus (PRCV). Using polymerase chain reaction amplified regions of PRCV isolates and nucleotide sequencing, a $681 \mathrm{bp}$ deletion in the 5 ' region of the $\mathrm{S}$ gene from PRCV isolate ISU-1 was identified. This deletion was located in the area of the S glycoprotein gene identified by the pD24 probe.
\end{abstract}

\section{INTRODUCTION}

Transmissible gastroenteritis virus (TGEV) causes severe diarrhea in swine (1). Although molecular studies on this virus have advanced our knowledge greatly, an efficacious vaccine and reliable diagnostic assay have not been developed. Furthermore, the recent discovery of porcine respiratory coronavirus (PRCV) has complicated the diagnosis of TGEV infected herds $(2,3,4)$.

Coronaviruses have been placed into antigenic groups based on serology $(5,6)$. 
Using virus neutralization assays, TGEV and PRCV appear to be antigenically identical (7). Other viruses which are grouped antigenically with TGEV and PRCV include feline infectious peritonitis virus (FIPV), feline enteric coronavirus (FECV), canine coronavirus (CCV), and human respiratory coronavirus (HCV-299E). Monoclonal antibodies have been developed which can distinguish TGEV and PRCV strains $(7,8)$. A competitive inhibition ELISA using non-neutralizing monoclonal antibodies was developed to distinguish serum antibodies from TGEV and PRCV infected pigs (8).

Diagnosis of TGEV infections using cDNA probes and hybridization was first reported by Shockley and coworkers (9). These investigators demonstrated the utility of dot blot hybridization to detect TGEV in clinical samples. Later, Benfield et al. (10) reported on the application of this assay to detect TGEV in fecal samples. The dot blot assay was comparable in sensitivity to conventional assays such as immunofluorescence and electron microscopy.

The appearance of PRCV in the United States prompted our laboratory to examine the use of dot blot hybridization for the differentiation of TGEV and PRCV infections. A nucleotide sequence comparison between TGEV and FIPV was reported in 1987 by Jacobs and coworkers (11). This study demonstrated a variable sequence region at the $5^{\prime}$ end of the $\mathrm{S}$ glycoprotein gene between these two antigenically related viruses. Therefore, we postulated that the $5^{\prime}$ end of the TGEV S glycoprotein may also contain sequence variability compared to other antigenically related coronaviruses including PRCV.

\section{MATERIALS AND METHODS}

\section{Viruses and Cells}

The virulent Miller strain of TGEV was used for the preparation of cDNA clones. The attenuated Purdue strain (P115) was used in dot blot hybridization studies. Other viruses used in dot blot studies were FIPV and FECV. Feline viruses FIPV and FECV were propagated in Crandell feline kidney cells ( $\mathrm{CrFK})$ cells. These viruses and cells wère obtained from J. F. Everman, Washington State University, Pullman Washington (12, 13). The ISU-1 and ISU-2 isolates of PRCV were obtained from H. Hill, Veterinary Diagnostic Laboratory, Iowa State University, Ames, Iowa (4). Swine testicular (ST) cells were used to propagate the TGEV and PRCV strains.

\section{Production of cDNA Clones and Probes}

The cDNA clones to TGEV were prepared from genomic RNA as previously described (10). The first strand cDNA reaction was primed using random calf-thymus DNA oligonucleotides and the second strand reaction was conducted using DNA polymerase I and RNase $\mathrm{H}$. The cDNA was tailed using dCTP and terminal transferase and annealed into the Pst I site of pUC9 which was Pst I cut and tailed with dGTP. Clones specific for the $\mathrm{S}$ glycoprotein gene were identified using colony blot hybridization (14). A probe prepared from Hpa-1600 (a gift from R. Wesley, National Animal Disease Center, United States Department of Agriculture, Ames, Iowa) was used in the colony blot assay. The Hpa-1600 cDNA contained 1,600 base pares (bp) of nucleotide sequence in the $\mathrm{S}$ glycoprotein gene of TGEV. All probes used in this study were prepared using $\left({ }^{32} \mathrm{P}\right) \mathrm{dCTP}$ (specific activity, $>600 \mathrm{Ci} / \mathrm{mmol}$; ICN Pharmaceuticals Inc., Irvine, California) and nick translation. 


\section{Dot Blot Hybridization Assays}

Viruses were harvested from cell cultures and treated with proteinase $\mathrm{K}(100 \mathrm{ug} / \mathrm{ml})$ at $37 \mathrm{C}$ for $45 \mathrm{~min}$. Each sample was extracted with phenol and chloroform before precipitation in ethanol at $-20 \mathrm{C}$. Precipitated RNA was collected by centrifugation and resuspended in $300 \mathrm{ul}$ of sterile water and an equal volume of SSC-formaldehyde solution (two parts $37 \%$ formaldehyde and three parts $20 \mathrm{X} \mathrm{SSC}$; $1 \mathrm{X} \mathrm{SSC}$ is $0.15 \mathrm{M} \mathrm{NaCl}$ plus $0.05 \mathrm{M}$ sodium citrate). The samples were incubated at $65 \mathrm{C}$ for $15 \mathrm{~min}$ and then applied to nylon hybridization membranes (Biotrans; ICN Biochemicals, Irvine, California) using a dot blot hybridization manifold (Bethesda Research Laboratories, Inc., Gaithersberg, Maryland).

Prehybridization and hybridization were conducted in buffer containing $5 \mathrm{X}$ SSC, $5 \mathrm{X}$ Denhardt solution $(0.1 \%$ [wt/vol] Ficoll, $0.1 \%$ [wt/vol] polyvinylpyrrolidone, $0.1 \%$ [wt/vol] bovine serum albumin), $50 \mathrm{mM}$ sodium phosphate ( $\mathrm{pH} 6.5$ ), 0.1\% SDS, 250 $\mathrm{ug} / \mathrm{ml}$ salmon sperm DNA, and $50 \%$ ( vol $/ \mathrm{vol}$ ) formamide. Prehybridization was conducted at $42 \mathrm{C}$ for $4 \mathrm{hr}$ and hybridization was conducted for $18 \mathrm{hr}$ at $42 \mathrm{C}$. Approximately $3 \times 10^{6} \mathrm{cpm}$ per membrane of each probe were added to the hybridization buffer. Following hybridization, the membranes were washed at room temperature in $2 \mathrm{X}$ SSC containing $0.1 \%(\mathrm{wt} / \mathrm{vol})$ SDS and then at $42 \mathrm{C}$ in $0.1 \mathrm{X} \mathrm{SSC}$ containing $0.1 \%$ (wt/vol) SDS before hybridization.

\section{Nucleotide Sequencing}

Nucleotide sequence analysis of ISU-1 was conducted on cDNA amplified using the polymerase chain reaction (PCR). Genomic RNA from ISU-1 was purified and a first strand cDNA was prepared as described above using random calf-thymus DNA oligonucleotides. Amplification of this CDNA was accomplished using a PCR kit (PerkinElmer Cetus, Norwalk, Connecticut) and two primers. Primer 1 (GGTCCATCAGTTACGCCGAA) was located in the 3 ' region of the adjacent polymerase gene and primer 2 (AAGGAAGGGTAAGTTGCTCA) was located in the 5' region of the $S$ glycoprotein gene (bases 1165 to 1185 ). The expected amplified product was 1250 bases in length. The PCR products were analyzed by agarose gel electrophoresis and Southern blot hybridization (15).

The gene 6 exonuclease (United States Biochemical Co., Cleveland, Ohio) was used to enzymatically alter the cDNA into single-stranded templates for sequencing. Dideoxy-chain termination sequence reactions were conducted using Sequenase (United States Biochemical Co.) and primers 1 and 2 (16).

\section{RESULTS}

\section{cDNA Probes}

Using the Hpa-1600 probe and colony blot hybridization, two cDNA clones were identified in the 5 ' region of the $S$ glycoprotein gene. One was designated pE21 and the other $\mathrm{pD24}$. The TGEV clone $\mathrm{pE} 21$ was $381 \mathrm{bp}$ in length and encompased bases 974 to 1355 from the 5' end of the S glycoprotein gene. The TGEV cDNA clone pD24 was located closer to the 5'end of the $S$ glycoprotein gene (bases 198 to 465 ) and was $267 \mathrm{bp}$ in length. On the basis of sequence homologies reported for TGEV and FIPV (11), pD21 was in a region of relatively high sequence homology $(87 \%)$ and pD24 was in a region of relatively low sequence heterology (49\%) (Fig. 1). 
48.8\% identity in 258 bp overlap

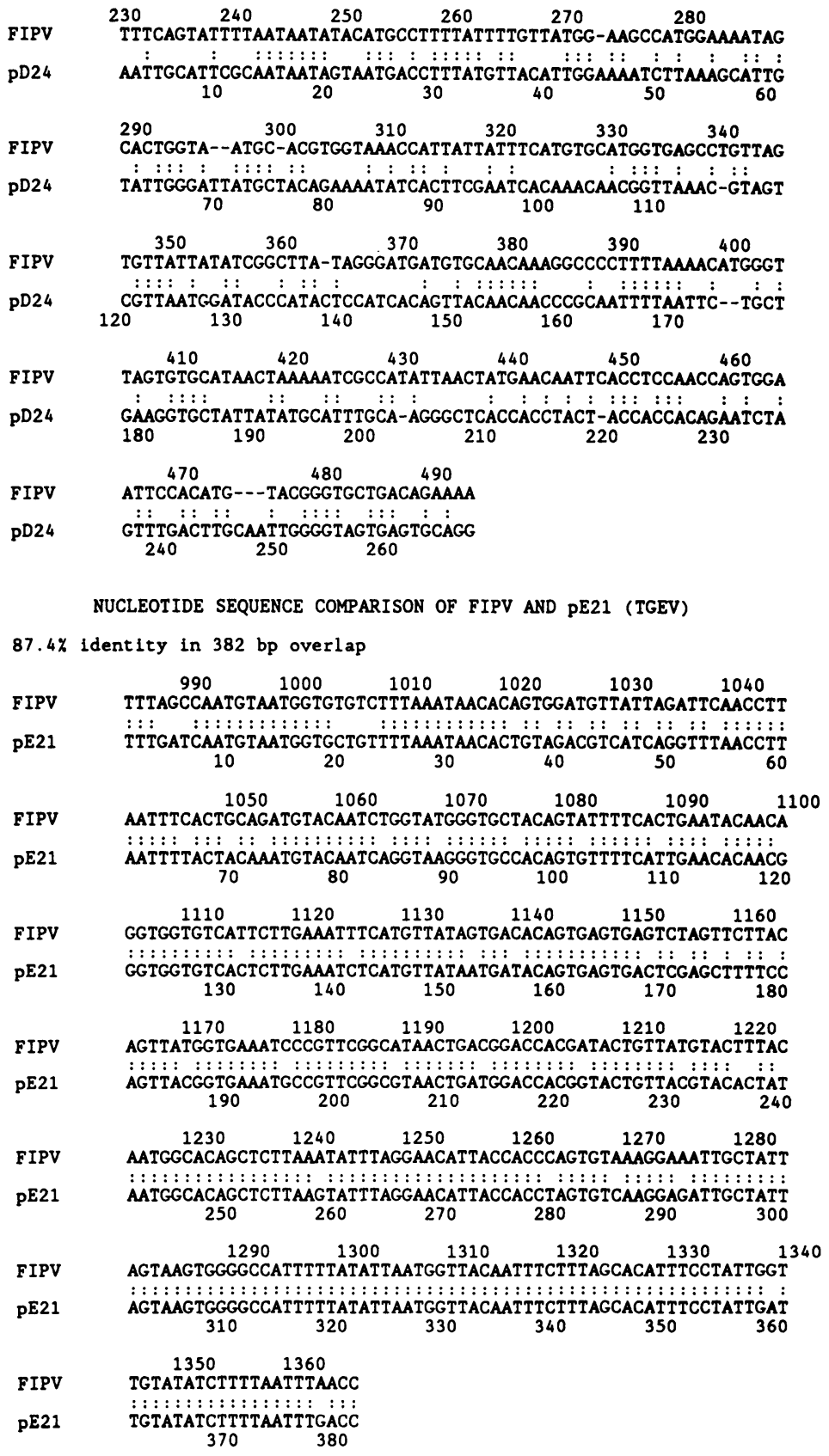

Figure 1. Nucleotide sequence comparison of TGEV cDNA clones pD24 and pE21 with the FIPV sequence published by Jacobs et al. (11).

\section{Dot Blot Hybridization}

Probes prepared using pE21 hybridized to TGEV (Miller and Purdue stains), PRCV (ISU-1 and ISU-3 strains), FECV, and FIPV. Probes prepared to pD24 however, only hybridized to the two TGEV strains. They did not hybridize to PRCV, FECV, and FIPV (Fig. 2). 

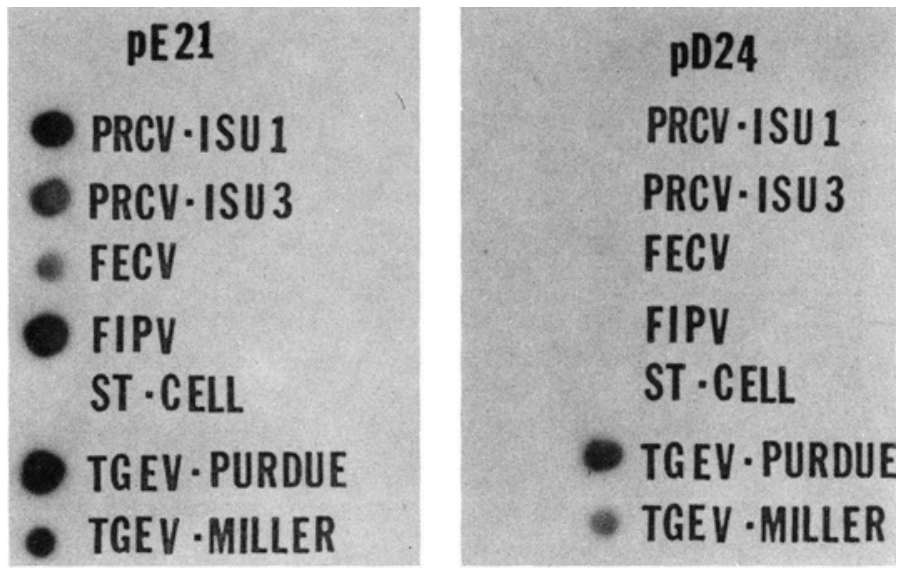

Figure 2. Dot blot hybridization using the TGEV cDNA pE21 and pD24 probes. Hybridization was conducted using $50 \%$ formamide at $42 \mathrm{C}$.

\section{PCR Amplification and Nucleotide Sequence Comparison}

The PCR products were analyzed using agarose gel electrophoresis and Southern blot hybridization. PCR amplified cDNA from the Miller TGEV strain was approximately $1250 \mathrm{bp}$ in length. Using the same primers, the PCR amplified cDNA from ISU-1 was approximately $580 \mathrm{bp}$ in length. These results indicated a deletion existed in this region of the PRCV isolate ISU-1. Probe pE21 hybridized to the PCR amplified products from TGEV and ISU-1 in a Southern blot hybridization assay (data not shown). Probe pD24 however, only hybridized to the TGEV PCR product.

Nucleotide sequencing of the ISU-1 PCR product confirmed the 681 base deletion (Fig. 3). This deletion begins 62 bases from the 5 ' end of the $\mathrm{S}$ glycoprotein gene.

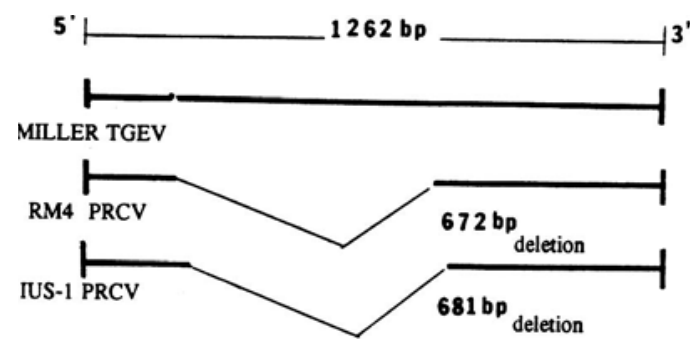

Figure 3. Schematic of the sequence comparisons among Miller strain TGEV, ISU-1 strain PRCV and RM4 strain PRCV. The deletion observed in the US PRCV isolate ISU-1, was very similar to that observed in the European RM4 PRCV isolate.

\section{DISCUSSION}

Diagnosis of TGEV infections is possible using dot blot hybridization (9). This assay has compared favorably with immunofluorescence and electron microscopy (10). We have demonstrated in this study that hybridization can also be used to differentiate TGEV from antigenically related coronaviruses including the PRCV isolates found in the US.

Our original hypothesis based on data reported by Jacobs et al. (11), was that the 
lack of hybridization of pD24 with PRCV and other antigenically related coronaviruses was due to heterologous sequences at the $5^{\prime}$ end of the $S$ glycoprotein gene. Nucleotide sequence data on ISU-1 demonstrated the lack of hybridization was due to a deletion in the sequence. Although European PRCV isolate RM-4 (17) was not tested in the hybridization assay, nucleotide sequence data indicates that this virus contains a similar deletion and probably could be distinguished from TGEV using the pD24 probe. Because sequence data for the $\mathrm{S}$ glycoprotein gene from FECV are not available, the basis for the observed lack of hybridization of probe pD24 to this virus is not known.

Since our original report in 1991 (18), others have also reported on the use of dot blot hybridization for the detection and differentiation of TGEV and PRCV isolates (19).

The dot blot hybridization assay has the potential to be an excellent diagnostic assay for TGEV infections. Currently, most assays rely on detecting virus or viral antigens in fecal samples. Shedding of the virus in fecal samples is a requirement for detecting TGEV in the dot blot hybridization assay. The length of time pigs shed virus following TGEV infection has not been studied. If the duration of shedding is short, this would limit the utility of dot blot hybridization as a practical diagnostic assay. However, the pD24 and pE21 probes may be more useful in other hybridization assays such as in situ hybridization or they could be used in combination with PCR which would increase the sensitivity of the dot blot hybridization assay.

\section{REFERENCES}

1. Saif, L. J., and E. H. Bohl. In. Diseases of swine, A. D. Leman et al. (ed), Iowa State University Press, Ames, Iowa. pp. 255-274, 1986.

2. Pensaert, M., P. Callebaut, and J. Vengote. Vet. Quart. 8(3):257-261, 1986.

3. Brown, I., S. Cartwright. Vet. Rec. 119:282-283, 1986.

4. Hill, H., J. B. Biwer, R. Wood, and R. Wesley. Proc. Am. Assn. of Swine Practitioners. 21:333-335, 1990.

5. Peterson, N. C., I. Ward, and W. L. Mengeling. Arch. Virol. 58:45-53, 1987.

6. Sturman, L. S., and K. V. Holmes. Adv. Virus Res. 28:35-112, 1983.

7. Callebaut, P., I. Correa, M. Pensaert, G. Jimenez, and L. Enjuanes. J. Gen. Virol. 69:1725-1730, 1988.

8. Callebaut, P., M. B. Pensaert, and J. Hooyberghs. Vet. Microbiol. 20:9-19, 1989.

9. Shockley, L. J., P. A. Kapke, W. Lapps, D. A. Brian, L. N. Potgieter, and R. Woods. J. Clin. Microbiol. 25:1591-1596, 1987.

10. Benfield, D. A., D. J. Jackwood, I. Bae, L. J. Saif, and R. D. Wesley. Arch. Vriol. 116:91-106, 1991.

11. Jacobs, L., R. J. De Groot, B. A. M. van der Zeijst, M. C. Horzinek, and W. Spaan. Virol. Res. 8:363-371, 1987.

12. McKeirnan, A. J., J. F. Evermann, A. Hargis, L. M. Miller, and R. L. Ott. Feline Pract. 11:16-20, 1981.

13. Pederson, N. C., J. F. Evermann, A. J. McKeirnan, and R. L. Ott. Am J. Vet. Res. 45:2580-2585, 1984.

14. Grunstein, M., and J. Wallis. Methods Enzymol. 68:379-388. 1979.

15. Southern, E. M. J. Mol. Biol. 98:503-517, 1975.

16. Sanger, F., S. Nicklen, and A. R. Coulson. Proc. Natl. Acad. Sci. USA 74:5463-5467, 1977.

17. Rasschaert, D. J. Duarte, and H. Laude. J. Gen. Virol. 71:2599-2607, 1990.

18. Bae, I., D. J. Jackwood, D. A. Benfield, L. J. Saif, R. D. Wesley, and H. Hill. J. Clin. Microbiol. 29:215-218, 1991.

19. Wesley, R. D., I. V. Wesley, and R. D. Woods. J. Vet. Diagn. Invest. 3:29-32, 1991. 